\title{
TAXONOMIA INTEGRATIVA REVELA UM NOVO CAMARÃO-DE-ESTALO CRÍPTICO DO COMPLEXO ALPHEUS MACROCHELES (HAILSTONE, 1835) (CARIDEA, ALPHEIDAE) NO ATLÂNTICO OCIDENTAL
}

\author{
Soledade, G.O. ${ }^{1,{ }^{*} ;}$ Terossi, M. ${ }^{3}$, Mantelatto, F.L. ${ }^{2}$ \& Almeida, A.O. ${ }^{1}$ \\ ${ }^{1}$ Universidade Federal de Pernambuco (UFPE), Campus Recife, Laboratório de Biologia de Crustáceos (LBC), \\ Departamento de Zoologia, Centro de Ciências Biológicas. \\ ${ }^{2}$ Universidade de São Paulo (USP), Campus Ribeirão Preto, Faculdade de Filosofia, Ciências e Letras de Ribeirão \\ Preto (FFCLRP), Laboratório de Bioecologia e Sistemática de Crustáceos (LBSC), Departamento de Biologia. \\ ${ }^{3}$ Universidade Federal do Rio Grande do Sul (UFRGS), Campus do Vale. Laboratório de Carcinologia. \\ *Autor correspondente: guidoosoledade@gmail.com
}

\begin{abstract}
Entre os inúmeros complexos de espécies crípticas existentes no altamente diverso gênero Alpheus, Alpheus macrocheles (Hailstone, 1835) é um dos que persistem sem uma total resolução taxonômica. Das sete espécies distribuídas no Atlântico, quatro apresentam registros para a costa brasileira. O maior número de registros é para Alpheus macrocheles que, em contrapartida, tem sua ocorrência incerta na costa brasileira por conta da inexistência de ilustrações e comparações morfológicas apropriadas nos registros prévios de ocorrência. Foi realizada uma exaustiva análise de caracteres morfológicos de parte dos exemplares desta espécie reportado para o Brasil e depositado no Museu de Oceanografia Professor Petrônio Alves Coelho (UFPE), bem como de espécimes adicionais obtidos através de coletas de dragagem ao largo de Recife-PE, em fevereiro de 2018. Foram observadas diferenças morfológicas com relação aos indivíduos do Atlântico Oriental. Os espécimes provenientes do Brasil se mostraram também morfologicamente distintos de $A$. amblyonyx Chace, 1972, espécie intimamente relacionada a $A$. macrocheles e de ocorrência no Mar do Caribe e Brasil. A análise genética de Inferência Bayesiana com o uso do gene mitocondrial $16 \mathrm{~S}$ corroborou estes resultados. O estabelecimento deste novo táxon é reforçado pela separação genética das demais espécies mais aparentadas. Este novo camarãode-estalo é até o momento restrito ao litoral norte/nordeste do Brasil, ocorrendo nos estados do Amapá, Pará, Ceará, Maranhão e Pernambuco (localidade-tipo, Recife). São fornecidas ilustrações dos caracteres diagnósticos e comparações com as demais espécies do complexo com ocorrência no Atlântico. O padrão de coloração da espécie é também ilustrado.
\end{abstract}

Palavras-chave: espécie nova, morfologia, biologia molecular, costa brasileira.

Financiamento: FACEPE, CNPq, FAPESP. 